\title{
Guest Editorial \\ How Can Cognitive-behaviour Therapy Contribute to the Promotion of Women's Health?
}

\author{
Monica O'Kelly \\ Monash University, Australia
}

$\mathrm{T}$

his special issue of Behaviour Change, in presenting a collection of papers on issues relating to women, clearly demonstrates the applicability of the cognitive-behavioural model to women's issues.

There are those with a feminist orientation that are critical of the cognitive-behavioural approach to women's issues. They reject the view that a woman's distress or experiences such as depression and anxiety can be caused by irrational beliefs, dysfunctional cognitions and maladaptive coping styles. In contrast they see them as resulting from a woman's socialisation within hierarchical, masculine symbolic structures. They furthermore assume that the cognitive-behavioural approach minimises context in favour of internal pathology in a standard "blaming the victim" error $(\mathrm{H}$. Gridley, personal communication, 2002).

The cognitive-behavioural model does not negate social context. The vicious cycle of sexrole stereotyping has been clearly outlined (Wolfe \& Naimark, 1991). From an early age both men and women receive messages from their social milieu regarding what is considered the appropriate way for them to think, feel and behave. By the time children have grown up they have internalised a belief system that can be regarded as their gender schema. For both men and women aspects of the social context and their gender related beliefs may not be constructive. To explore and describe gender related beliefs does not imply blame but is an attempt to understand. Once we understand we are in a better position to work toward change. It is admirable to take social action and work toward social justice and I hope cognitive-behaviour therapists join in this process. I believe, however, that cognitive-behaviour therapists have a particular contribution to make in empowering both women and men to aware of and change their internalised gender beliefs that are counterproductive and self and other limiting.

This collection of papers contributes to the cognitive-behaviour therapist's understanding of women in a number of areas. Some of the papers relate to issues that are specific to women (such as juggling motherhood with career; Dingle; O'Kelly), others explore problems that have a higher incidence of occurrence in women (such as eating disorders and depression; Crafti), and others explore aspects relevant to women in situations that confront both men and women (hospitalisation; Allen; Polomani $\&$ Moore). The papers will be valuable to both researchers and practitioners who are interested in women's issues and contributing to the process of social change.

\section{References}

Wolfe. J., \& Naimark. H. (1991). Psychological messages and social context: Strategies for increasing RET's effectiveness with women. In M. Bernard (Ed.), Using rational-emotive therapy effectively. New York: Plenum Press.

Address for correspondence: Monica O'Kelly, PhD, Department of Psychology, Monash University, Monash, Victoria, 3800, Australia. 